\title{
Hubungan Tingkat Pendidikan Ibu dengan Kejadian Stunting
}

\author{
Dedeh Husnaniyah, Depi Yulyanti, Rudiansyah \\ STIKes Indramayu, Jl. Wirapati Sindang - Indramayu, Sindang, Kabupaten \\ Indramayu, Jawa Barat \\ Email :d.husnaniyah@gmail.com
}

$\begin{array}{ll}\text { Diterima tanggal } & : 15 \text { April } 2020 \\ \text { Direvisi tanggal } & : 10 \text { Mei } 2020 \\ \text { Dipublikasikan tanggal } & : \text { 11 Juni } 2020\end{array}$

\begin{abstract}
Abstrak
Latar Belakang dan Tujuan: Stunting di sebabkan karena kekurangan gizi kronis dan infeksi berulang pada periode 1.000 Hari Pertama Kehidupan (HPK). Permasalahan gizi pada periode tersebut akan memunculkan beragam masalah kesehatan. Tingkat pengetahuan ibu menjadi salah satu faktor dalam pemenuhan kebutuhan gizi pada keluarga khusunya anak. Tujuan Penelitian ini adalah untuk mengidentifikasi hubungan tingkat pendidikan ibu dengan kejadian stunting.

Metode: penelitian deskriptif dengan rancangan penelitian cross sectional study. Populasi penelitian adalah ibu yang memiliki anak balita di wilayah kerja puskesmas Kandanghaur Indramayu. Pengambilan sampel dilakukan dengan tekhnik accidental sampling sebayak 308 responden.

Hasil: sebanyak $16(5,20 \%)$ responden dengan tingkat pendidikan ibu tidak sekolah/tidak tamat Sekolah Dasar, sebanyak 134 (43,50\%) responden dengan tingkat pendidikan Sekolah Dasar, sebanyak 90 (29,20\%) responden dengan tingkat pendidikan SMP, sebanyak $61(19,80 \%)$ responden dengan tingkat pendidikan SMA, sebanyak $7(2,30 \%)$ responden dengan tingkat pendidikan Perguruan Tinggi. Sebanyak $116(38,6 \%)$ anak dengan stunting dan sebanyak $189(61,4 \%)$ anak yang tidak stunting. Terdapat hubungan antara tingkat pendidikan ibu dengan kejadian stunting dengan nilai $\mathrm{p}$ value $=0,005(<0,05)$. Simpulan dan Implikasi: tingkat pengetahuan ibu memiliki peranan yang signifikan dengan kejadian stunting. Calon ibu diharapkan dapat meningkatkan pendidikan formalnya, dikarenakan pendidikan merupakan cara praktis agar ibu lebih mudah dalam menyerap informasi kesehatan.
\end{abstract}

Kata Kunci: Stunting; Tingkat pendidikan ibu

Sitasi: Husnaniyah D, Yulyanti D \& Rudiansyah. (2020). Hubungan tingkat pendidikan ibu dengan kejadian stunting. The Indonesian Journal of Health Science. 12(1), 57-64

Copyright: () 2020 Husnaniyah et al. This is an open-access article distributed under the terms of the Creative Commons Attribution License, which permits unrestricted use, distribution, and reproduction in any medium, provided the original author and source are credited.

Diterbitkan Oleh: Universitas Muhammadiyah Jember ISSN (Print): 2087-5053

ISSN (Online): 2476-9614 


\begin{abstract}
Introduction: Stunting is caused by chronic malnutrition and recurrent infections during the first 1,000 days of life (HPK). Nutritional problems in that period will cause various health problems. Mother's level of knowledge is one of the factors in fulfilling the nutritional needs of families, especially children. The purpose of this study was to identify the relationship between maternal education and stunting case.

Methods: Descriptive study with a cross sectional study design. The study population was mothers who had children under five in the working area of the Kandanghaur Indramayu Community Health Center. Sampling was done by accidental sampling technique of 308 respondents.

Result: $16(5.20 \%)$ respondents with education level of mothers who did not attend school / did not complete elementary school, 134 (43.50\%) respondents with primary education level, 90 (29.20\%) respondents with Junior high school education level, 61 (19.80\%) respondents with a high school education level, and $7(2.30 \%)$ respondents with college education level. $116(38.6 \%)$ children were stunted and 189 (61.4\%) children were not stunted. There is a relationship between the level of maternal education and the incidence of stunting with $p$ value $=0.005(<0.05)$.
\end{abstract}

Conclusion: mother's level of knowledge has a significant role with the case of stunting. Prospective mothers are expected to improve their formal education, because education is a practical way to make it easier for mothers to absorb health information

Keywords : Mother's education level; Stunting

\section{PENDAHULUAN}

Stunting adalah kondisi di mana tinggi badan seseorang lebih pendek di bandingkan dengan tinggi badan orang lain yang seusianya (Kementrian Desa, Pembangunan Daerah tertinggal, dan Transmigrasi, 2017). Stunting di sebabkan karena kekurangan gizi kronis dan infeksi berulang pada periode 1.000 Hari Pertama Kehidupan (HPK).

Menurut World Health Organization (WHO) prevalensi stunting menjadi permasalahan kesehatan masyarakat jika prevalensinya $20 \%$ atau lebih. Diperkirakan terdapat 162 juta stunting pada tahun 2012, Jika trend berlanjut tanpa upaya penurunan, diproyeksikan akan menjadi 127 juta pada tahun 2025 (Kementerian Kesehatan RI, 2016). Prevalensi stunting di Indonesia memperlihatkan persentase status gizi balita pendek (pendek dan sangat pendek) di Indonesia tahun 2007 adalah (36,8\%), tahun 2013 adalah $(37,2 \%)$, dan pada tahun 2015 $(35,6 \%)$ (Kementerian Kesehatan RI, 2007 \& Riskesdas, 2013). Prevalensi masalah pendek pada Balita di Jawa Barat ditemukan 35,4\% balita stunting (Kementerian Kesehatan RI. 2007 \& Riskesdas, 2007).

Berdasarkan laporan tahunan Penimbangan Balita Dinas Kesehatan Kabupaten Indramayu pada tahun 2015 penemuan Balita stunting dengan diadakannya penimbangan dengan ukuran Antropometri adalah sejumlah 5.638 
jiwa $(7,69 \%)$ dan pada tahun 2016 sejumlah 11.173 jiwa $(9,9 \%)$, pada tahun 2017 sejumlah 24.427 jiwa $(10,8 \%)$ dan dapat diartikan terjadi peningkatan jumlah balita stunting di Kabupaten Indramayu (Dinas Kesehatan Kabupaten Indramayu, 2015, 2016 \& 2017).

Tahun 2017 diketahui bahwa ada 5 wilayah kerja puskesmas dengan prevalensi stunting terbesar diantaranya puskesmas Kandanghaur dengan persentase stunting 1337 jiwa $(22,28 \%)$, Lelea 1005 jiwa $(15,63 \%)$, Sindang 1390 jiwa $(15,49 \%)$, Kerangkeng 1770 jiwa $(15,03 \%)$, dan Gabus Wetan 1087 jiwa (13,06\%), dengan jumlah balita stunting di Kabupaten Indramayu sebesar 24.427 jiwa (10,8\%) (Dinas Kesehatan Kabupaten Indramayu, 2017).

Stunting pada balita harus mendapatkan perhatian khusus karena dapat menyebabkan terhambatnya pertumbuhan fisik, perkembangan mental dan status kesehatan pada anak. Studi terkini menunjukkan bahwa anak yang mengalami stunting berkaitan dengan prestasi di sekolah yang buruk, tingkat pendidikan yang rendah dan pendapatan yang rendah saat dewasa. Anak yang memiliki stuning memiliki kemungkinan lebih besar tumbuh menjadi individu dewasa yang tidak sehat dan miskin. Anak dengan stunting memiliki kerentanan untuk menderita penyakit tertentu, baik penyakit menular maupun Penyakit tidak menular (PTM), serta peningkatan resiko overweight dan obesitas. Keadaan overweight dan obesitas jangka panjang dapat meningkatkan resiko degeneratif. Kasus stunting pada anak dapat dijadikan prediktor rendahnya kualitas sumber daya manusia suatu negara. Stunting menyebabkan buruknya kemampuan kognitif, rendahnya produktivitas, serta meningkatkan resiko penyakit mengakibatkan kerugian jangka panjang bagi ekonomi Indonesia (Trihono, Atmarita, Tjandrarini DH, Irawati A, Utami NH, Tejayanti, et al, 2015).

Stunting erat kaitannya dengan tingkat pendidikan. Menurut Riskesdas (2013) menunjukkan bahwa kejadian stunting banyak di pengaruhi oleh pendapatan dan pendidikan orangtua yang rendah, khususnya ibu (3). Ibu memiliki Peranan penting dalam pengasuh anak mulai dari pembelian hingga penyajian makanan. Apabila pendidikan dan pengetahuan ibu tentang gizi rendah akibatnya ia tidak mampu untuk memilih hingga menyajikan makanan untuk keluarga yang memenuhi syarat gizi seimbang (Soekirman, 2000).

Hal ini sejalan dengan penelitian yang dilakukan di Meksiko bahwa pendidikan ibu sangat penting dalam hubungannya dengan pengetahuan gizi dan pemenuhan gizi keluarga khusunya anak, karena ibu dengan pendidikan rendah antara lain akan sulit menyerap informasi gizi sehingga anak beresiko mengalami stunting (Leroy JF, Habicht JP, de cossio TG, and Ruel MT, 2014 \& Hizni A, Yulia M, dan Gamayanti IL, 2010). Dengan demikian maka perlu diketahui hubungan tingkat pendidikan ibu dengan kejadian stunting.

\section{METODE PENELITIAN}

Jenis penelitian ini deskriptif dengan rancangan penelitian Studi Potong Lintang (Cross Sectional Study), dimana pengukuran variabel 
dependen dan variabel independen dilakukan pada saat yang sama dan sifatnya sesaat.

Populasi pada penelitian ini adalah ibu yang memiliki anak balita, tinggal di wilayah kerja puskesmas Kandanghaur, mampu membaca dan menulis, dan bersedia menjadi responden. Sampel penelitian dihitung menggunakan rumus Slovin dengan margin eror sebesar 5\% sehingga sampel yang didapatkan sebanyak 308 orang. Penelitian di laksanakan di seluruh desa yang merupakan wilayah Kerja Puskesmas Kandanghaur Kabupaten Indramayu pada bulan Juli 2019.

Penelitian dilakukan setelah keluar Ethical Clearance (EC) dari committee ethics Universitas Gajah Mada dengan nomor surat Ref. No. : KE/FK/0788/EC/2019. Sebelum melakukan wawancara dengan responden, peneliti memberikan penjelasan terlebih dahulu kepada responden meliputi tujuan penelitian, manfaat dan menjamin kerahasian identitas dan data yang diberikan. Setelah itu peneliti baru meminta persetujuan penelitian kepada responden. Setelah informed consent didapatkan, peneliti baru melakukan penelitian dengan melakukan wawancara, observasi dan pengukuran.

Data primer diperoleh dengan melakukan observasi dan wawancara kepada ibu dengan menggunakan kuesioner dan melakukan pengukuran kembali kepada anaknya. Penentuan stunting atau tidaknya dihitung menggunakan WHO antropometri. Sedangkan data sekunder diperoleh dari puskesmas Kandanghaur. Analisis data yang digunakan adalah analisis univariat untuk melihat distribusi frekuensi tingkat pendidikan ibu dan stunting, analisis bivariat digunakan untuk melihat hubungan antara tingkat pendidikan ibu dengan kejadian stunting. Adapun alat uji statistik yang digunakan yaitu Aplikasi statistik dengan komputer (Dahlan. M. Sopiyudin, 2011).

\section{HASIL}

Berdasarkan Tabel 1 diketahui bahwa pendidikan ibu paling banyak yaitu Sekolah Dasar (SD) sebanyak $134 \quad(43,5 \%)$ responden dan anak dengan kejadian stunting terbanyak yaitu tidak stunting sebanyak $189 \quad(61,4 \%)$ responden.

Sedangkan tabel 2 menunjukkan bahwa dari 134 responden yang berpendidikan SD dan memiliki anak dengan stunting sebanyak $67(50 \%)$ responden, ibu yang berpendidikan SD dan memiliki anak tidak stunting sebanyak 67 $(50 \%)$ responden. Hasil analisis dengan menggunakan chi-square diperoleh nilai $\mathrm{p}$ value $=0,005<$ 0,05 maka dapat di simpulkan bahwa ada hubungan anatara pendidikan ibu dengan kejadian stunting.

\section{PEMBAHASAN}

Stunting merupakan keadaan dimana status gizi kurang yang bersifat kronik pada masa pertumbuhan dan perkembangan sejak awal kehidupan. Menurut World Health Organization (WHO) mengatakan bahwa stunting di kondisikan dengan nilai Z-score tinggi badan menurut umur (TB/U) kurang dari -2 standar deviasi (SD), secara global sekitar 1 dari 4 balita mengalami stunting (Magarwati, A., \& Astuti, M. A, 2018). 
Tabel 1. Distribusi Frekuensi Tingkat Pendidikan Ibu dan Kejadian Stunting $(\mathrm{n}=308)$

\begin{tabular}{lcc}
\hline Kategori & Jumlah (n) & Presentase (\%) \\
\hline Tingkat Pendidikan & & \\
Tidak sekolah/ Tidak tamat SD & 16 & 5,2 \\
SD & 134 & 43,5 \\
SMP & 90 & 29,2 \\
SMA & 61 & 19,8 \\
PT & 7 & 2,3 \\
Kejadian Stunting & & \\
Stunting & 119 & 38,6 \\
Tidak Stunting & 189 & 61,4 \\
\hline
\end{tabular}

Tabel 2. Hubungan Tingkat Pendidikan dengan Kejadian Stunting $(\mathrm{n}=308)$

\begin{tabular}{|c|c|c|c|c|c|c|c|}
\hline \multirow{3}{*}{ Pendidikan Ibu } & \multicolumn{4}{|c|}{ Stunting } & \multirow{2}{*}{\multicolumn{2}{|c|}{ Jumlah }} & \multirow{3}{*}{$\begin{array}{c}\text { Nilai } \\
\mathbf{p}\end{array}$} \\
\hline & \multicolumn{2}{|c|}{ Stunting } & \multicolumn{2}{|c|}{$\begin{array}{c}\text { Tidak } \\
\text { Stunting }\end{array}$} & & & \\
\hline & $\mathbf{n}$ & $\%$ & $\mathbf{n}$ & $\%$ & $\mathbf{n}$ & $\%$ & \\
\hline Tidak sekolah & 6 & 37,5 & 10 & 62,5 & 16 & 5,2 & \\
\hline SD & 67 & 50 & 67 & 50 & 134 & 43,5 & \\
\hline SMP & 30 & 33,3 & 60 & 66,7 & 90 & 29,2 & 0,005 \\
\hline SMA & 14 & 23 & 47 & 77 & 61 & 19,8 & \\
\hline PT & 2 & 28,6 & 5 & 71,4 & 7 & 2,3 & \\
\hline Total & 119 & 38,6 & 189 & 61,4 & 308 & 100 & \\
\hline
\end{tabular}

Kejadian stunting sering dijumpai khususnya pada anak usia 12-36 bulan dengan prevalensi sebesar 38,3-41,5\%. Stunting pada anak usia di bawah lima tahun biasanya kurang disadari dikarenakan perbedaan anak yang stunting dengan anak yang normal pada usia tersebut tidak terlalu di lihat. Usia di bawah lima tahun merupakan masa keemasan dalam menentukan kualitas sumber daya manusia yang di lihat dari segi pertumbuhan fisik maupun kecerdasan, sehingga hal ini harus di dukung oleh status gizi yang baik. Seorang anak yang mengalami stunting pada masa ini cenderung akan sulit mencapai tinggi badan yang optimal pada periode selanjutnya (Magarwati, A., \& Astuti, M. A, 2018). Salah satu faktor yang mempengaruhi kejadian stunting adalah tingkat pendidikan ibu.

Ibu rumah tangga berperan dalam pengambilan keputusan konsumsi pangan. Penyajian bahan makanan untuk seluruh anggota rumah tangga menjadi tugas pokok ibu rumah tangga. Oleh karena itu, semakin tinggi tingkat pendidikan ibu rumah tangga maka akan semakin tinggi pula kemampuan dalam hal pengambilan keputusan konsumsi rumah tangga terutama untuk memenuhi kebutuhan gizi seluruh anggota keluarga (Arida, dkk, 2015).

Berdasarkan hasil penelitian didapatkan bahwa dari 134 responden yang yang berpendidikan Sekolah Dasar (SD) dan memiliki anak dengan stunting sebanyak 67 
(50\%) responden, ibu yang berpendidikan Sekolah Dasar (SD) dan memiliki anak tidak stunting sebanyak 67 (50\%) responden. Hasil analisis dengan menggunakan chisquare diperoleh nilai $\mathrm{p}$ value $=$ $0,005$ ( $\mathrm{p}<0,05)$ maka dapat di simpulkan bahwa ada hubungan anatara pendidikan ibu dengan kejadian stunting di wilayah kerja Puskesmas Kandanghaur Indramayu. Hasil penelitian ini sejalan dengan penelitian Hizni (2010) yang menyatakan bahwa ibu yang memiliki pendidikan rendah beresiko memiliki anak dengan stunted 2,22 kali lebih besar di bandingkan dengan ibu berpendidikan tinggi (Hizni A, Yulia M, dan Gamayanti IL, 2010). Tingkat pendidikan, khususnya tingkat pendidikan ibu mempengaruhi derajat kesehatan. Hal ini terkait dengan peranan ibu yang paling banyak pada pembentukan kebiasaan makan anak, karena ibulah yang mempersiapkan makanan mulai mengatur menu, berbelanja, memasak, menyiapkan makanan dan mendistribusikan makanan. Menurut Wong (1995) dalam Natalina (2015) mengatakan bahwa dalam memberikan nutrisi pada anak, ibu yang mempunyai peran dalam menentukan variasi makanan dan mengidentifikasi kebutuhan nutrisi yang diperlukan oleh anggota keluarganya (Natalina, R. Diyan, P dan Kristiawati, 2015). Menurut Astari (2008) dalam Mustamin (2018) Ibu yang memiliki pengetahuan gizi baik diharapkan mampu menyediakan makanan dengan jenis dan jumlah yang tepat agar anak dapat tumbuh dan berkembang secara optimal (Mustamin, Asbar R, dan Budiawan, 2018).
Menurut Dekkar LH (2010) dalam Rahayu A dan Khairiyati L (2014) menyatakan bahwa konsumsi makanan bagi setiap orang terutama anak usia 1-2 tahun harus selalu memenuhi kebutuhan. Konsumsi makanan yang kurang akan menyebabkan ketidakseimbangan proses metabolisme di dalam tubuh. Apabila hal ini terjadi terus menerus akan terjadi gangguan pertumbuhan dan perkembangan seperti stunting (Rahayu A, dan Khairiyati L, 2014). Sehingga tingkat pengetahuan ibu merupakan salah satu komponen yang tidak bisa diabaikan.

\section{SIMPULAN}

Terdapat hubungan antara tingkat pendidikan ibu dengan kejadian stunting, dimana semakin rendah tingkat pendidikan ibu maka semakin besar risiko balita mengalami stunting.

\section{SARAN}

Diperlukan intervensi oleh petugas kesehatan di puskesmas dalam meningkatkan pengetahuan ibu terkait pencegahan stunting, karena pengetahuan tidak hanya didapat dari pendidikan formal melainkan dapat diperoleh dari pendidikan non formal seperti penyuluhan, media, dan beberapa sumber informasi yang dapat meningkatkan pengetahun ibu khususnya mengenai pencegahan stunting.

\section{DAFTAR PUSTAKA}

Arida. (2015). Analisis ketahanan pangan rumah tangga berdasarkan proporsi pengeluaran pangan dan konsumsi energi. Skripsi 
Dinas Kesehatan Kabupaten Indramayu. (2015). Laporan data Stunting di Kabupaten Indramayu.

Dinas Kesehatan Kabupaten Indramayu. (2016). Laporan data Stunting di Kabupaten Indramayu.

Dinas Kesehatan Kabupaten Indramayu. (2017). Laporan data Stunting di Kabupaten Indramayu.

Hizni A, Yulia M, dan Gamayanti IL. (2010). Status stunted dan hubungannya dengan perkembangan anak balita di wilayah pesisir pantai utara Kecamatan Lemahwungkuk Kota Cirebon. Jurnal Gizi Klinik Indonesia. 6:131-137.

Kementerian Kesehatan RI. (2007). Riset Kesehatan Dasar (Riskesdas). 2013. Jakarta : Badan Penelitian dan Pengembangan Kesehatan.

Kementerian Kesehatan RI. (2016). Infodatin pusat data dan informasi kementerian kesehatan RI. Situasi Balita Pendek. Jakarta

Kementrian Desa, Pembangunan Daerah tertinggal, dan Transmigrasi. (2017). Buku saku desa dalam penanganan stunting. Jakarta

Kementrian Perencanaan Pembangunan

Nasional/Badan Perencanaan Pembangunan Nasional. (2007). Rencana aksi nasional pangan dan gizi 2006-2010. Jakarta

Leroy JF, Habicht JP, de cossio TG, and Ruel MT. (2014). Maternal education mitigates the negative effects of higher income on the double burder of child stunting and maternal overweight in rural Mexico. The Jurnal of Nutrition. 5:765-770.

Magarwati, A., \& Astuti, M. A. (2018). Pengetahuan ibu pola makan dan status gizi pada anak stunting usia 1-5 tahun di Kelurahan Bangetayu Kecamatan Genuk Semarang. The Indonesian Journal of Nutrition. 6,(2) retrieved from https://ejournal.undip.ac.id/i ndex.php/jgi/article/view/19 175

Mustamin, Asbar R, dan Budiawan (2018). Tingkat pendidikan ibu dan pemberian asi eksklusif dengan kejadian stunting pada balita di Provinsi di Sulawesi Selatan. Media Gizi Pangan. Vol. 25 Edisi 12018

Natalina, R. Diyan, P dan Kristiawati. Hubungan pola asuh dengan status gizi balita di posyandu tulip wilayah rindang benua kelurahan pahandut palangkaraya. Jurnal Ilmu Kesehatan.Vol 1 No. 19.

Rahayu A, dan Khairiyati L (2014). Risiko pendidikan ibu terhadap kejadian stunting pada anak 6-23 bulan. Skripsi

Soekirman. (2000). Ilmu gizi dan aplikasinya untuk keluarga dan masyarakat. Jakarta : Direktoral Jendral Pendidikan Tinggi, Departemen Pendidikan Nasional.

Trihono, Atmarita, Tjandrarini DH, Irawati A, Utami NH, Tejayanti, et al. (2015). 
Pendek (stunting) di

Indonesia, masalah dan solusinya. Jakarta: Lembaga

Penerbit Balitbangkes. 